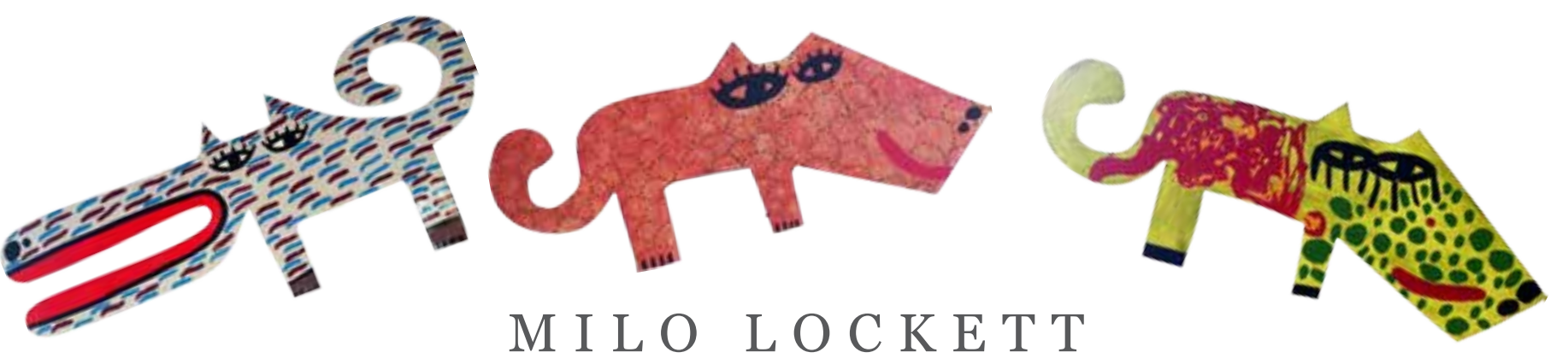

\section{UNA VIDA DEDICADA AL ARTE}

Milo Lockett es un artista plástico chaqueño, autodidacta, que comenzó su carrera luego de trabajar varios años en la industria textil.

En 2002 cerró su fábrica y estampadora textil, y abandonó completamente sus actividades empresariales para dedicarse por entero a la pintura.

De nacionalidad argentina, nacido el 1 de Diciembre de 1967, vive y trabaja en Resistencia, su ciudad natal. Desde su taller, situado en Irigoyen 456 "B", Milo logró crear en poco tiempo, una identidad pictórica que lo convirtió en un éxito de ventas sin precedentes.

Sus referentes se encuentran en la obra de Jorge de la Vega, Nigro, Macció y Deira.

El público de Milo Lockett abarca desde grandes coleccionistas a jóvenes empleados y profesionales que están buscando su primera obra de arte.

Milo Lockett dona anualmente un promedio de 40 obras para subastas a beneficio del Hospital Pediátrico de Resistencia, trabajo realizado con adolescentes dentro de un proyecto de prevención de HIV - Cruz Roja Argentina. Además, ha colaborado para UNICEF en el proyecto "Un Minuto por mis Derechos" en el $7^{\circ}$ Encuentro de Niños y Jóvenes escultores bajo el tema "Los Monstruos de Berni y Juanito Laguna”.

Ha realizado talleres masivos de pintura al aire libre en el Festival de la Triple Frontera, Paraguay, Brasil y Argentina, Chaco, Jujuy, Corrientes, Misiones, Santa Fe y Buenos Aires.

\section{PREMIOS Y RECONOCIMIENTOS}

> Premio Puente General Belgrano.

$>$ Premio INADI.

> Premio Estilo. Canal 5 de Noticias.

> Premio Salón Nacional Museo Rosa Galisteo, Sta. Fe.

> Ciudadano ilustre de la ciudad de Resistencia.

> Visitante ilustre de la ciudad de Mar del Plata.

> Premio Nacional Solange Guez.

> Premio Internacional: logo del foro

internacional de la mujer.

$>2^{0}$ premio Salón Regional de Artes Visuales 2008.

$>$ Cow Parade Bs. As. 2006 con la vaca

"subí que te llevo".

> Revelación ArteBA 2006.

> Premio Regional OSDE 2005 “El araguazú quiere unos mimos".

\section{MILO EN EL MUNDO}

Hamburgo, Alemania.

Berna, Suiza.

San Pablo Arte, Brasil.

Consulado argentino en New York, Estados Unidos.

Pintadas urbanas en subtes, Miami.

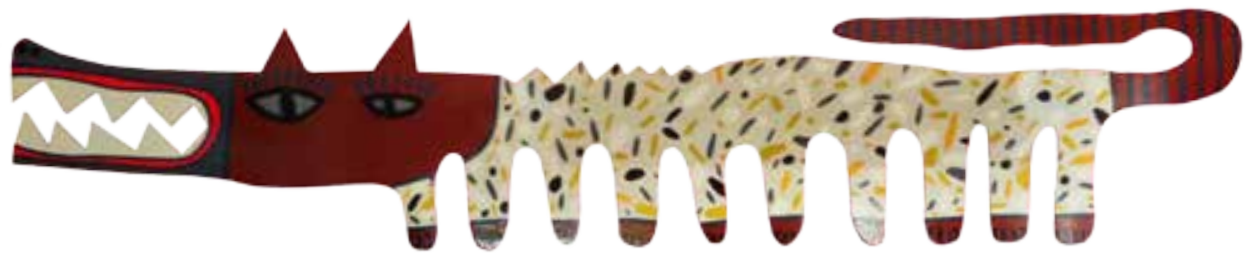




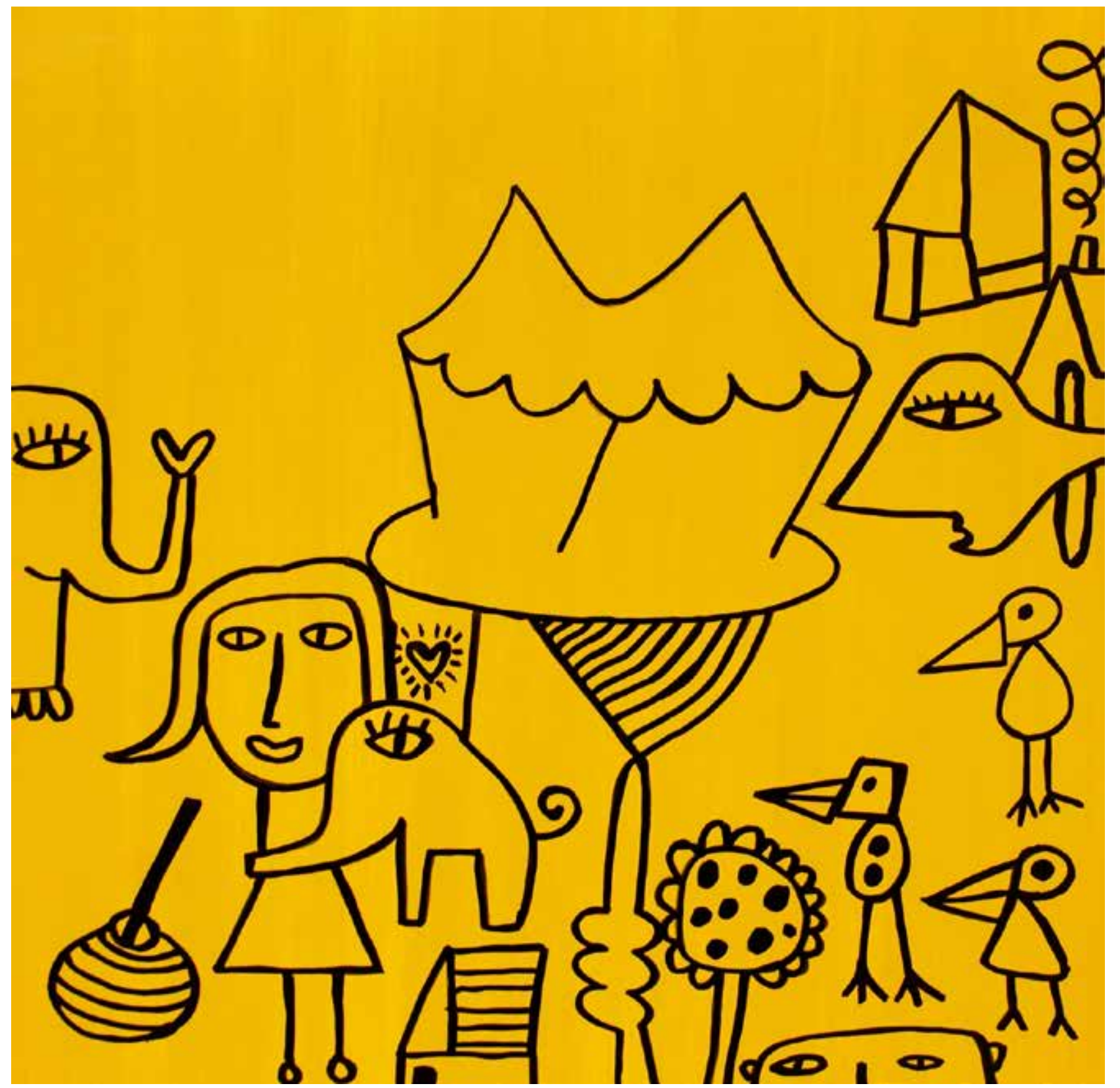

M I L O L O C K E T T

Resistencia-Chaco-Argentina 


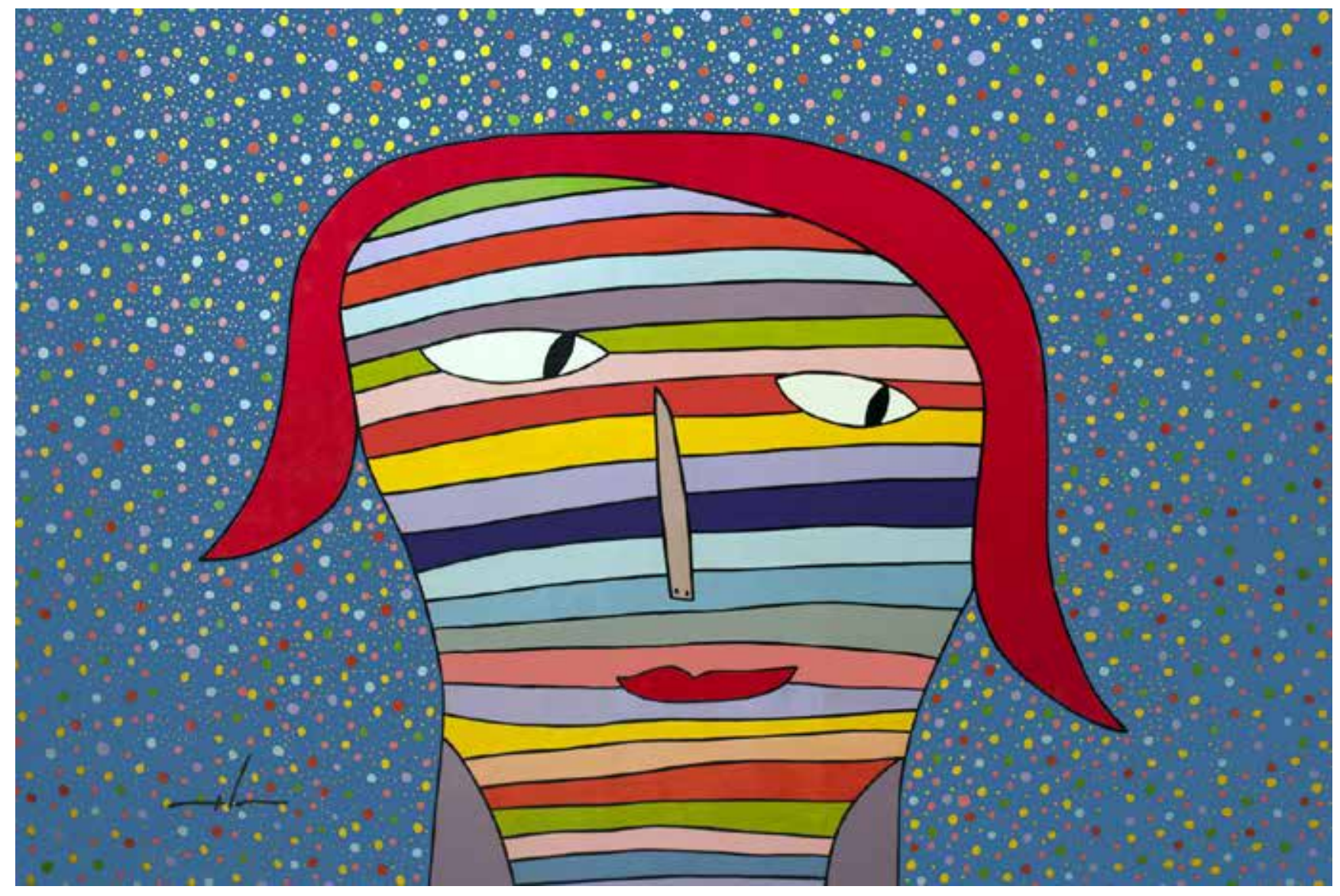

M I L O L O C K E T T

Resistencia-Chaco-Argentina 


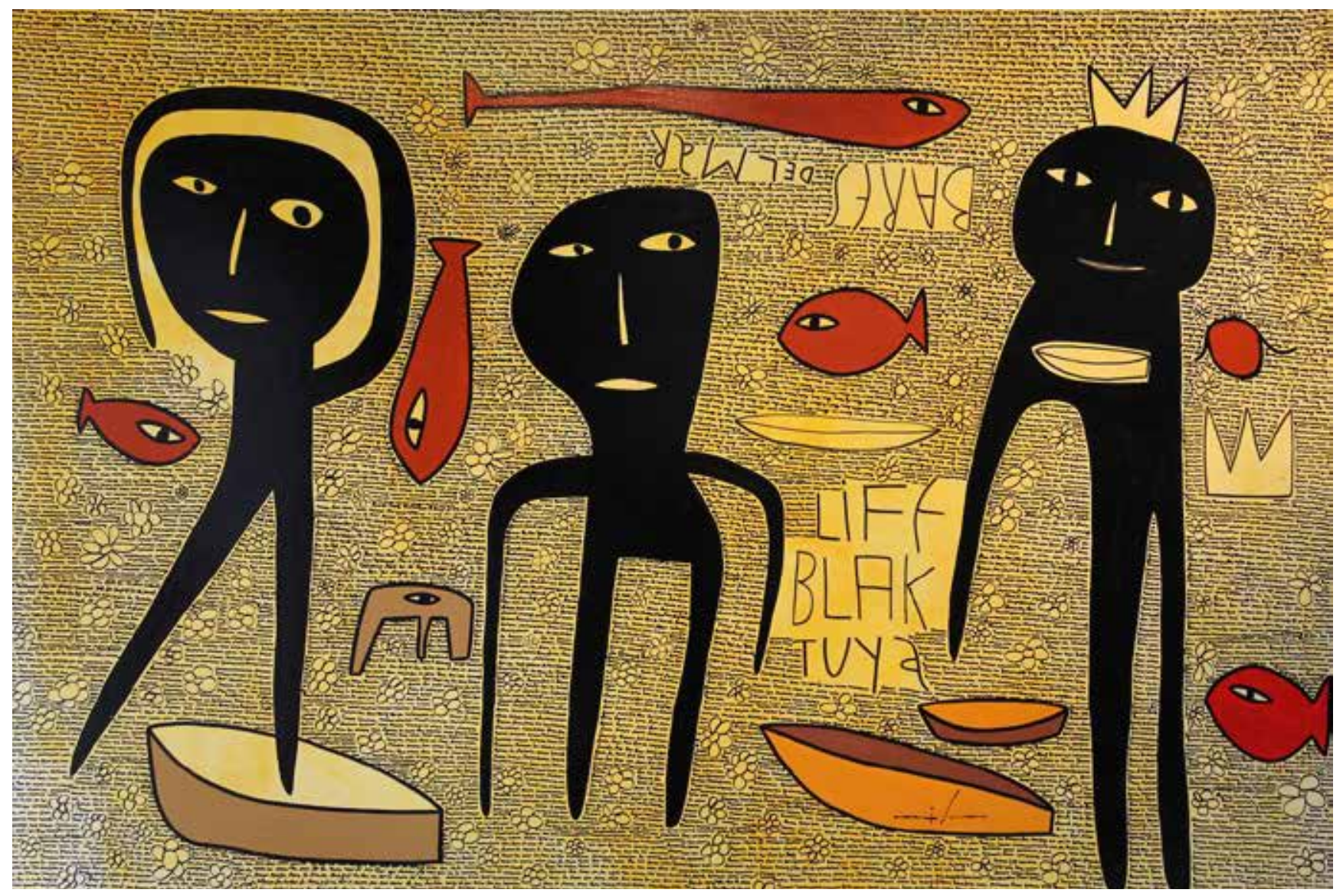

M I L O L O C K E T T

Resistencia-Chaco-Argentina 


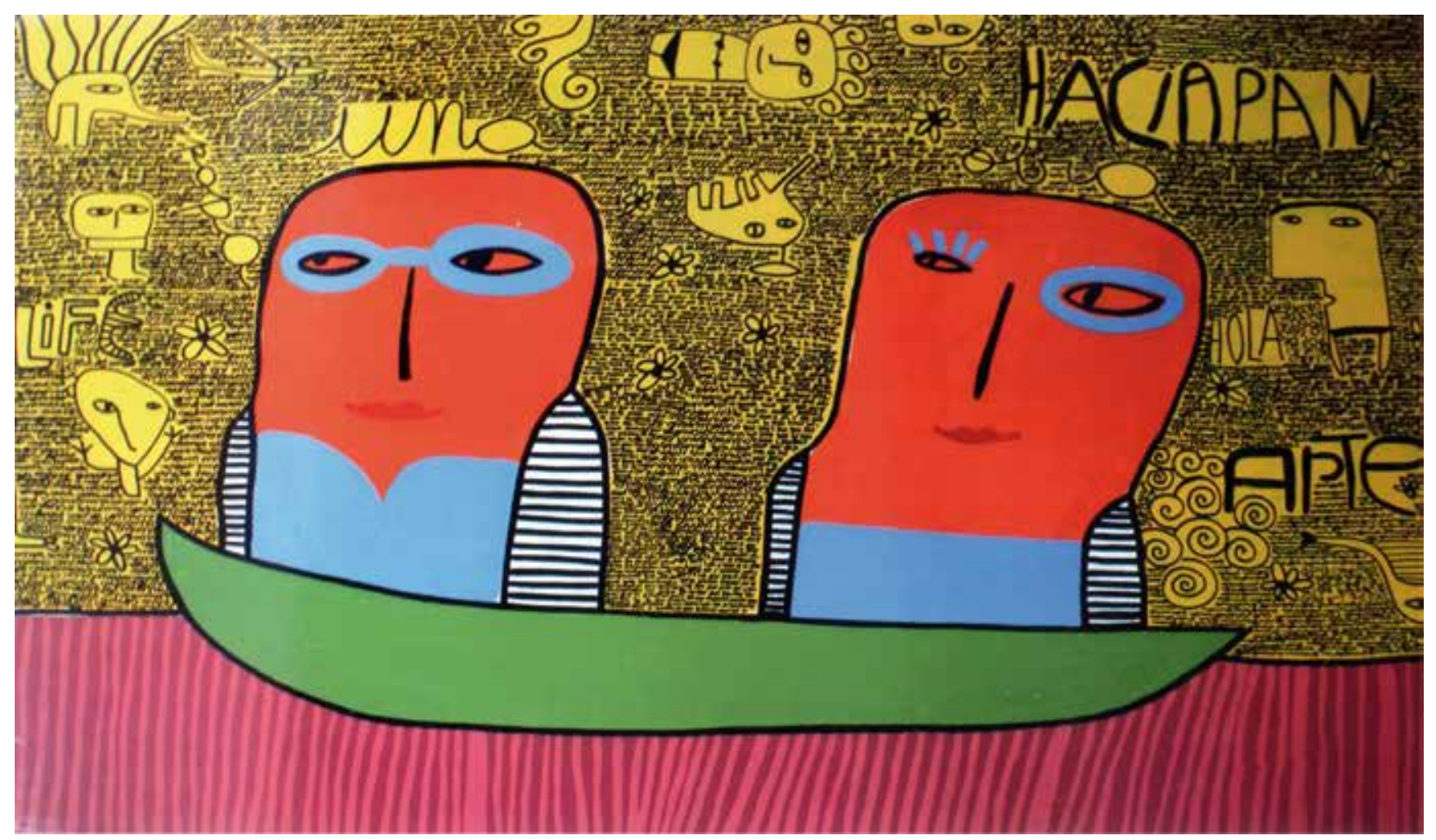

M I L O L O C K E T T

Resistencia-Chaco-Argentina 


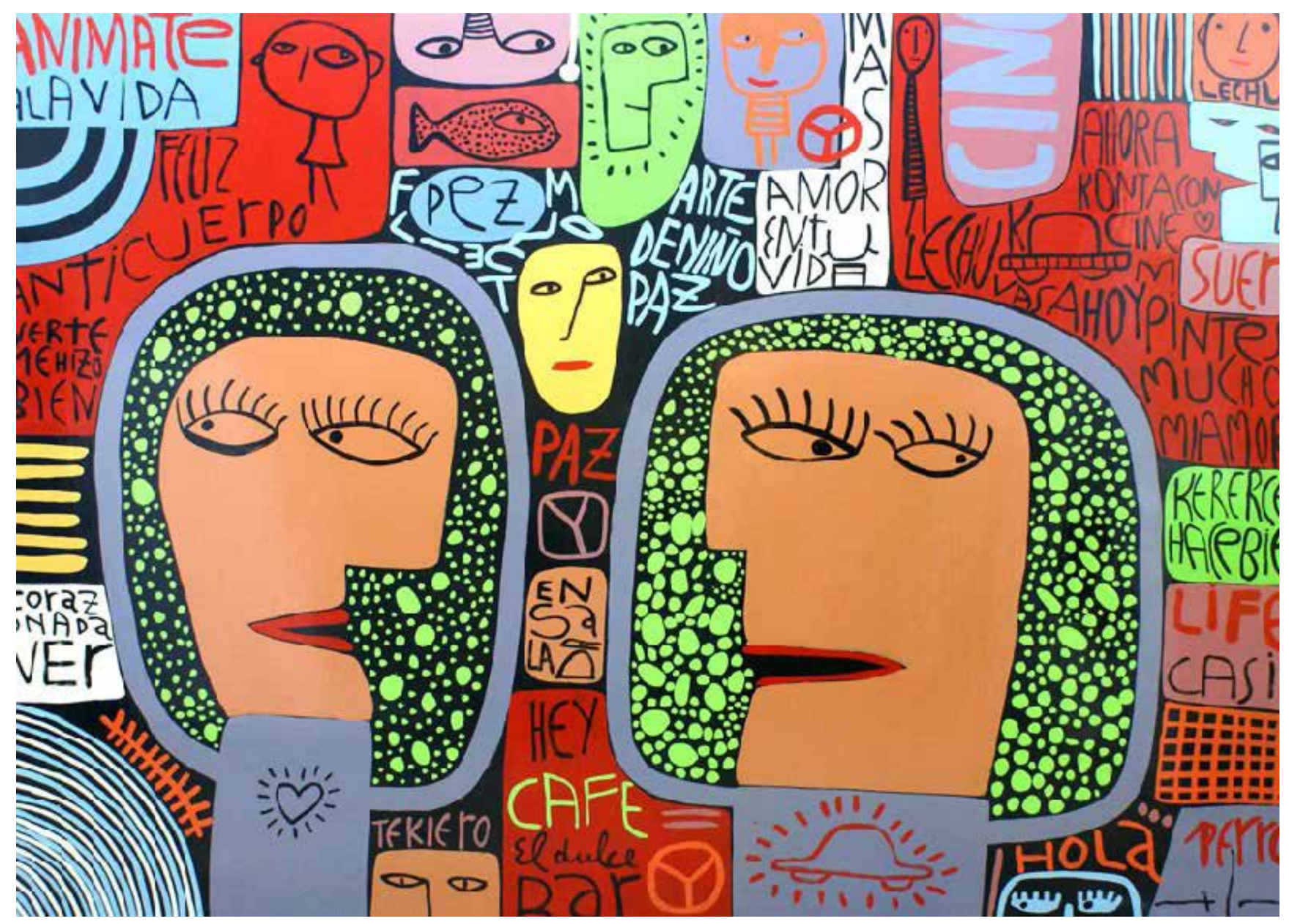




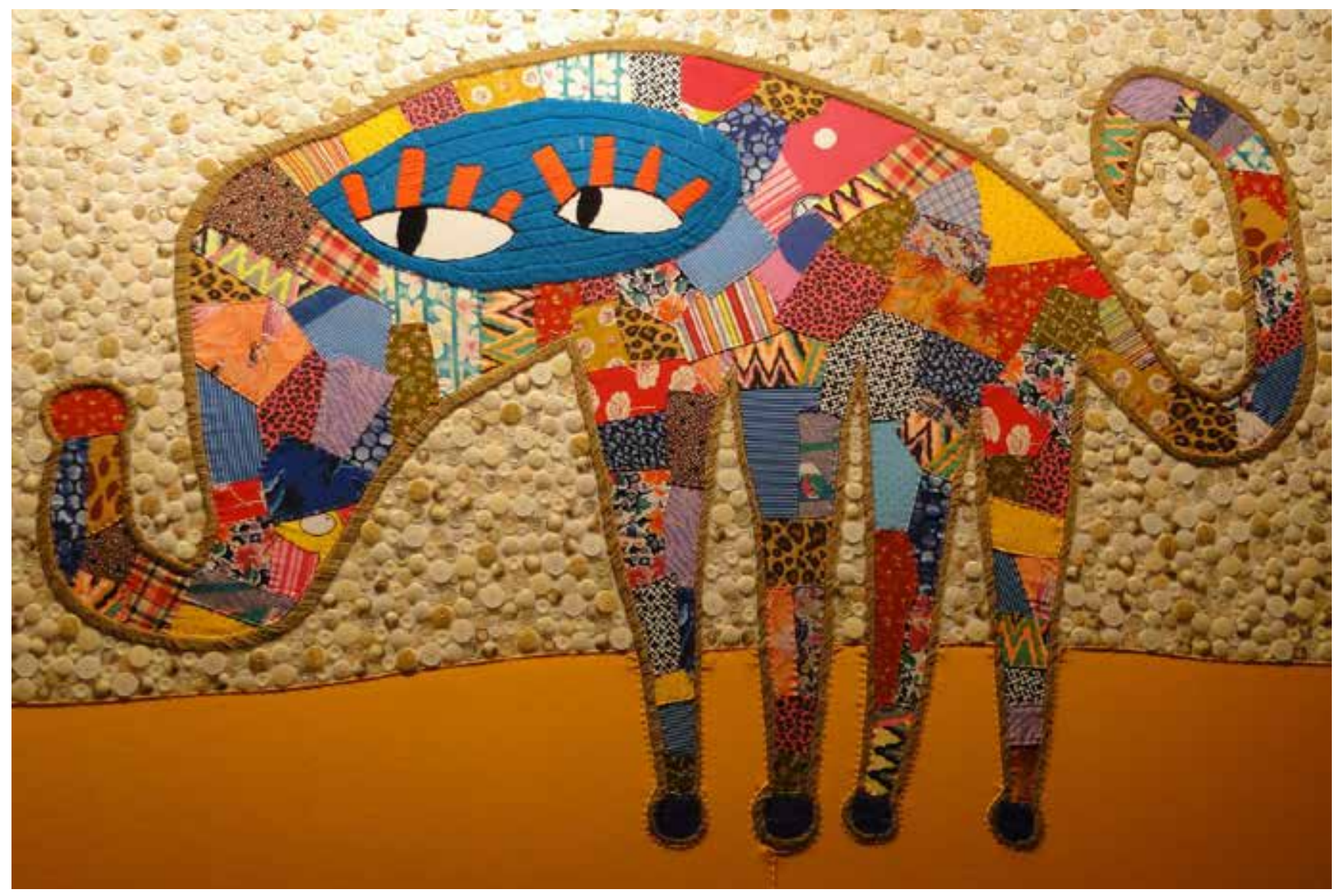

M I L O L O C K E T T

Resistencia-Chaco-Argentina 


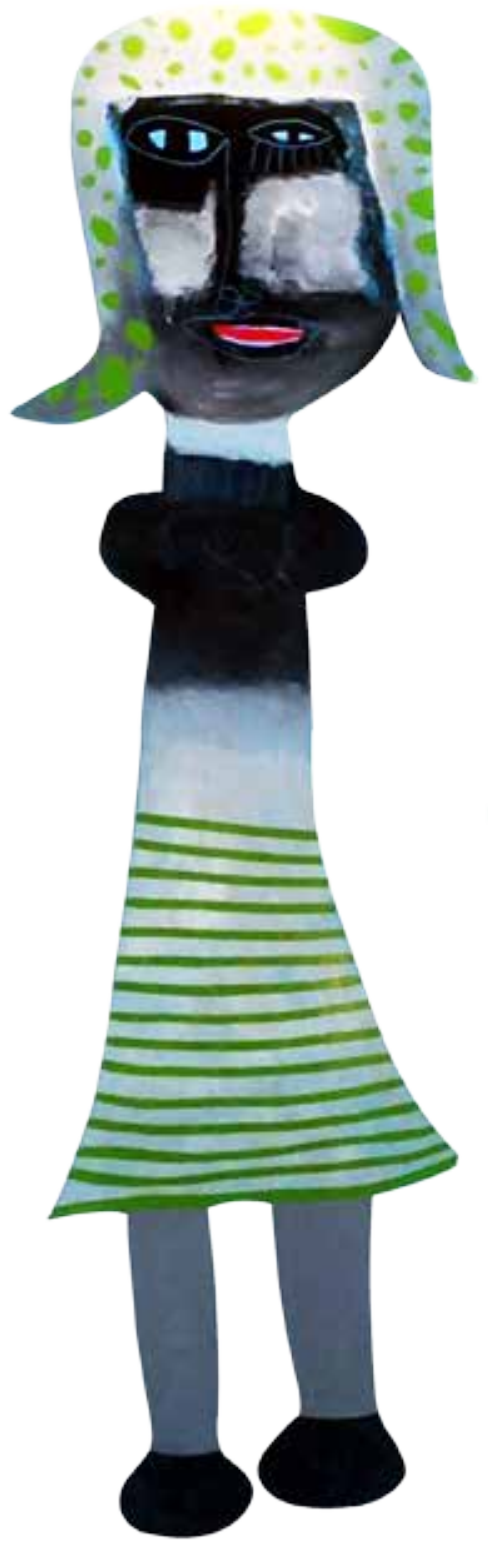

M I L O L O C K E T T

Resistencia-Chaco-Argentina 


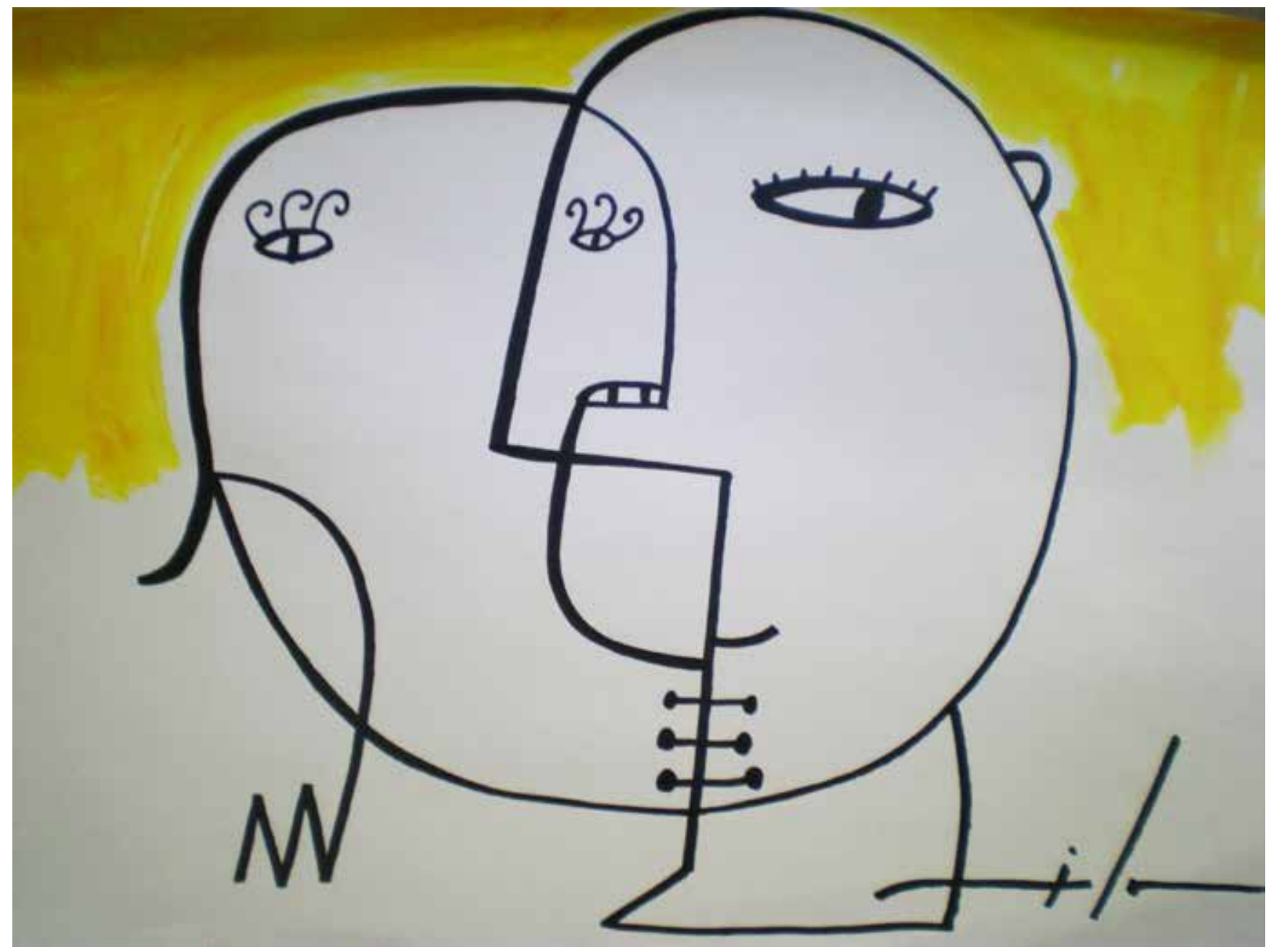

M I L O L O C K E T T

Resistencia - Chaco - Argentina 


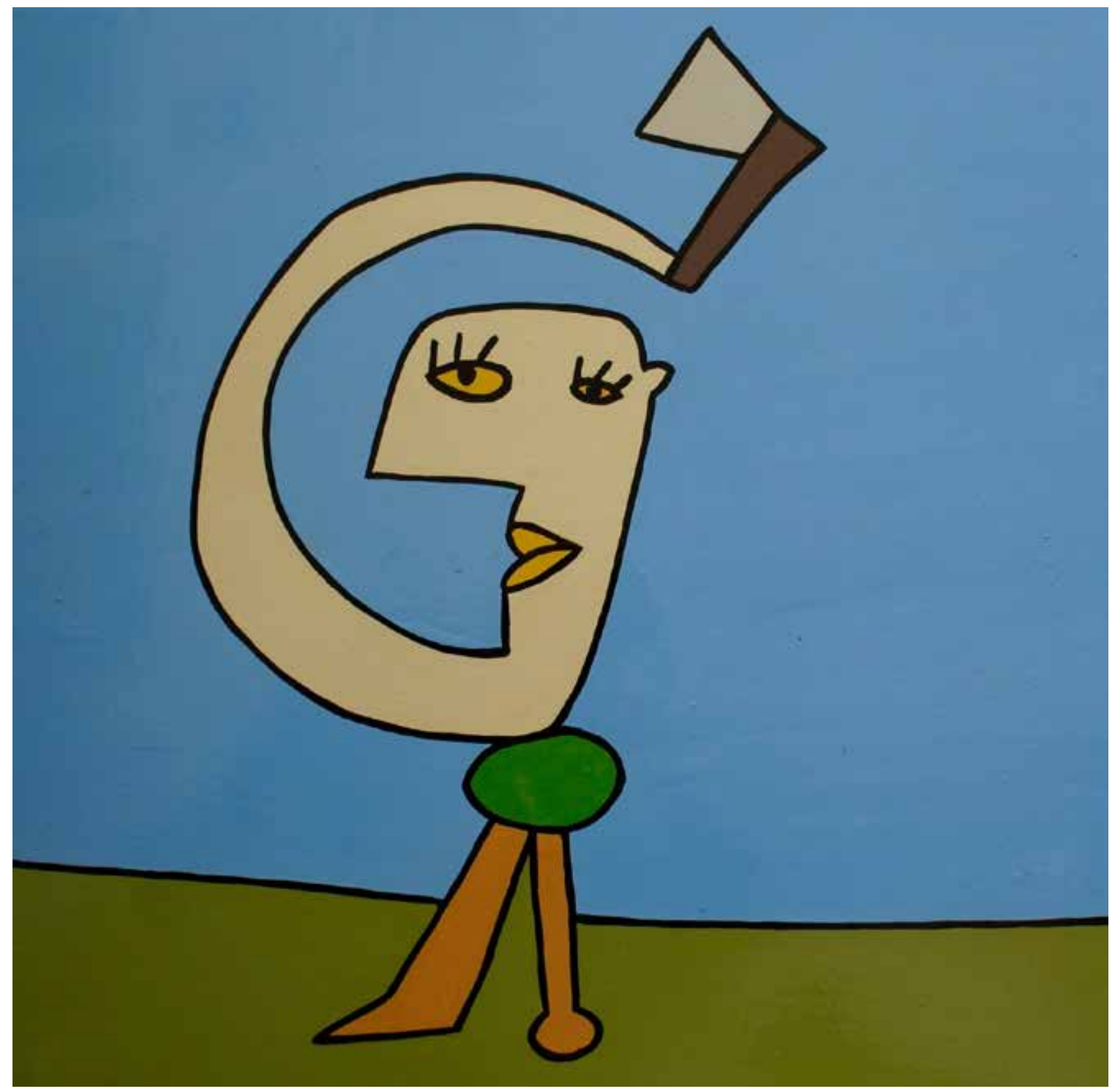

M I L O L O C K E T T

Resistencia-Chaco-Argentina 